RESEARCH ARTICLE

\title{
Early Maladaptive Schemas in Eating Disordered Patients With or Without Non-Suicidal Self-Injury
}

\author{
Els Pauwels ${ }^{1,2,3 *}$, Eva Dierckx ${ }^{2,3}$, Katrien Schoevaerts ${ }^{2}$ \& Laurence Claes ${ }^{1,4}$ \\ ${ }^{1}$ Department of Psychology, University of Leuven, Leuven, Belgium \\ ${ }^{2}$ Psychiatric Hospital Alexianen Tienen, Tienen, Belgium \\ ${ }^{3}$ Department of Psychology and Educational Sciences, Vrije Universiteit Brussel, Brussels, Belgium \\ ${ }^{4}$ Faculty of Medicine and Health Sciences, University of Antwerp, Campus Drie Eiken, Wilrijk, Belgium
}

\begin{abstract}
This study investigates early maladaptive schemas (EMSs) in function of eating disorder (ED) subtypes (restrictive/bulimic) and the presence/absence of non-suicidal self-injury (NSSI). Female inpatients $(N=491)$ completed the Young Schema Questionnaire and the Self-Injury Questionnaire. The influence of ED subtype and the presence/absence of NSSI and their interaction on the EMS were investigated by means of a MANCOVA. The results showed main effects of ED subtype and the presence of NSSI on EMS. Patients with bulimia scored significantly higher on insufficient self-control and emotional deprivation, which are more related to cluster B compared with restrictive patients, whereas restrictive patients scored significantly higher on social undesirability, failure to achieve, subjugation and unrelenting standards compared with patients with bulimia that are more related to cluster C. Patients with ED with NSSI reported significantly higher EMS levels compared with patients without NSSI, suggesting that they could be of particular interest to benefit from schema therapy. Copyright (c) 2016 John Wiley \& Sons, Ltd and Eating Disorders Association.
\end{abstract}

Received 12 October 2015; Revised 9 May 2016; Accepted 18 May 2016

Keywords

early maladaptive schemas; eating disorders; nonsuicidal self-injury

\section{*Correspondence}

Els Pauwels, Department of Psychology, University of Leuven, Liefdestraat 10, 3300 Tienen, Belgium.

Email: Els.pauwels@fracarita.org

Published online in Wiley Online Library (wileyonlinelibrary.com) DOI: 10.1002/erv.2460

\section{Introduction}

Early maladaptive schemas (EMSs) play an important role in the development and maintenance of psychopathology, including eating disorders (Cooper, Wells, and Todd, 2004; Waller, 2003). EMS, as described by Young and Pijnaker (1999), are defined as implicit beliefs about one's self and about the relationship with the environment. The EMSs are considered to be pervasive themes that form the core of one's self-concept. Notwithstanding their maladaptive nature, these EMSs are self-perpetuating and are considered to be relatively stable over time (Young, Klosko, and Weishaar, 2003). The EMSs are categorized into five higher order schema domains representing unmet emotional needs in childhood: (1) 'disconnection' with EMS emotional deprivation, mistrust/ abuse, abandonment, social isolation and defectiveness/shame; (2) 'impaired autonomy' with EMS social undesirability, failure to achieve, dependence/incompetence, enmeshment, vulnerability to harm and illness; (3) 'impaired limits' with EMS entitlement/ grandiosity and insufficient self-control/self-discipline; (4) 'other directedness' with EMS subjugation and self-sacrifice; and (5) 'inhibition' with EMS emotional inhibition and unrelenting standards.

Several studies have shown strong associations between EMSs and personality disorders. Pauwels et al. (2013) found significant associations between cluster $\mathrm{C}$ personality disorders and the EMS: dependence/incompetence, social undesirability and subjugation and between cluster B personality disorders and the EMS: insufficient self-control and mistrust. Additionally, high levels of cluster $\mathrm{C}$ personality disorders (avoidance, dependent, obsessive-compulsive) are more prevalent in restrictive ED subtypes, whereas cluster B personality disorders (narcissistic, antisocial, histrionic, borderline) are more prevalent in bulimic ED subtypes (Godt, 2002; Claes, Vandereycken, and Vertommen, 2005). Given the strong association between EMS and personality disorders, one would expect EMS differences across ED subtype. However, research focusing on EMS differences across the different subtypes are scarce, and results are inconclusive. This might be because of methodological shortcomings (e.g. small sample sizes, studies only focusing on some of the diagnostic categories,...). Furthermore, none of the existing research controlled for ED severity, although it has been shown that EMS levels are highly related with the amount of psychopathology (Pugh, 2015) and comorbid clinical symptoms, such as depression or obsessivecompulsive disorder (Cooper and Hunt, 1998; Voderholzer et al., 2014). Table 1 shows an overview of studies focusing on EMS differences between different ED diagnostic categories.

Despite the fact that non-suicidal self-injury (NSSI) is highly prevalent in ED (e.g. Claes and Vandereycken, 2007), probably sharing some common aetiology (e.g. childhood trauma, low self-esteem) (Jacobson and Luik in Claes and Muehlenkamp, 


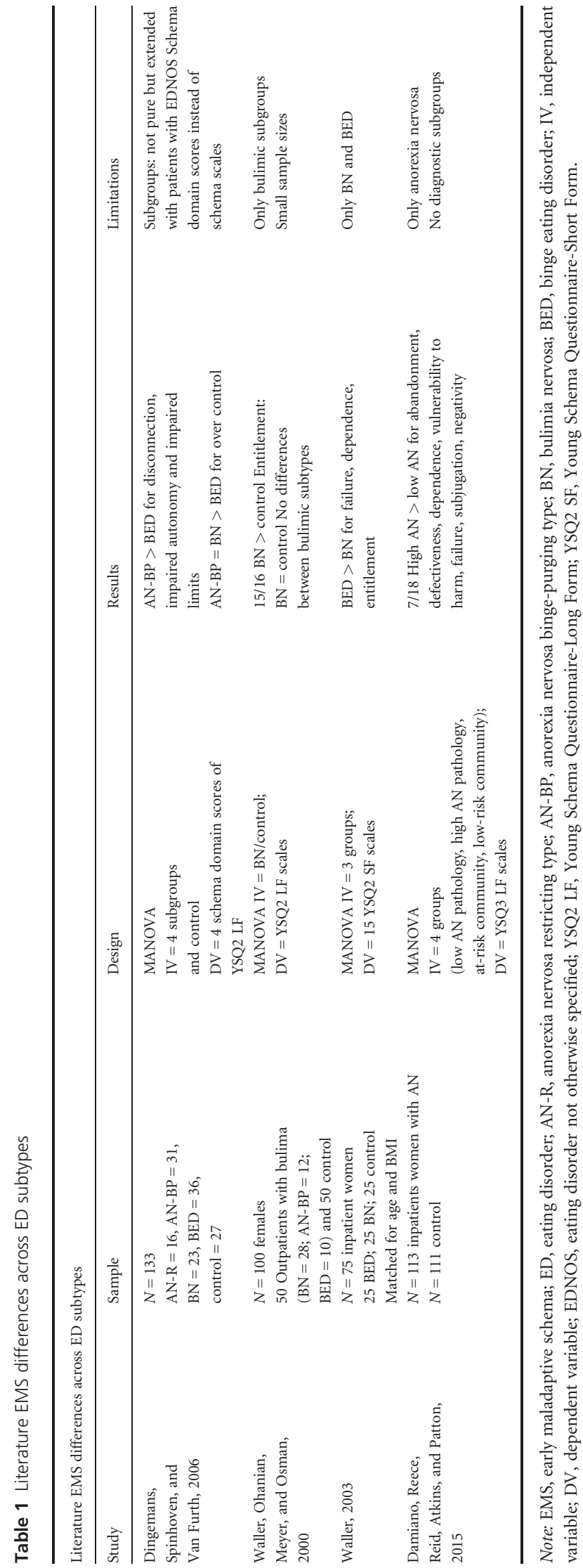

2014), to our knowledge, no research today has focused on the specific role of EMS in patients with ED with or without NSSI.

NSSI refers to the deliberate and direct injury of one's own body tissue without suicidal intent (Claes and Vandereycken, 2007) and is highly prevalent in patients with ED. A study of Claes and Muehlenkamp (2014) has shown that up to $72 \%$ of patients with ED also engage in NSSI. However, the prevalence of NSSI seems to vary across ED subtypes, being more prevalent among purging subtypes of ED compared with restrictive ones (Svirko and Hawton, 2007). Moreover, the co-occurrence of NSSI and $\mathrm{ED}$ is related to more personality pathology (Claes and Muehlenkamp, 2014; Islam et al., 2015), and given the strong relationship between personality pathology and higher levels of EMS (Pauwels et al., 2013), we would expect higher levels of EMSs in ED with NSSI (Young et al., 2003).

Remarkably, only a few studies have investigated differences in EMS between participants with or without NSSI. Table 2 shows an overview of the two studies that investigated EMS differences in patients with and without NSSI. Based on these two community studies, the lifetime presence of NSSI seems to be related with higher EMS levels and more psychopathology.

In this study, we will investigate the influence of ED subtype and presence/absence of NSSI and their interaction on EMSs. The specific aims of the present study were twofold. First, we explored the prevalence of NSSI across the different ED subtypes, expecting higher prevalence of NSSI among purging types. Second, we investigated whether EMSs differed significantly in function of ED subtype, the presence/absence of NSSI and/or their interaction. Based on our literature review, we expected that restrictive patients with ED will show higher levels of cluster C-related EMSs compared with patients with bulimia (e.g. unrelenting standards), whereas patients with bulimia will show higher levels of cluster B-related EMSs (e.g. insufficient self-control) compared with restrictive patients (Luck, Waller, Meyer, Ussher, and Lacey, 2005; Pauwels et al., 2013). Moreover, we hypothesized to find higher levels of EMS with NSSI compared with those patients with ED without NSSI.

\section{Method}

\section{Participants and procedure}

In total, 491 female inpatients with ED of a psychiatric hospital in Belgium participated in this study. All patients were admitted at the treatment unit for eating disorders. Data were gathered between 2008 and 2014. The ED sample consisted of four different subtypes of ED according to DSM-IV (American Psychiatric Association, 2000) criteria: 189 patients (38.5\%) met criteria for anorexia nervosa restricting type (AN-R; $\left.M_{\text {age }}=21.43, S D=6.52\right)$, 80 patients $(16.3 \%)$ met criteria for anorexia nervosa binge-purging type (AN-BP; $\left.M_{\text {age }}=21.5, S D=5.32\right), 113$ patients $(23 \%)$ met criteria for bulimia nervosa (BN; $\left.M_{\text {age }}=21.49, S D=5.10\right)$ and 109 patients $(22.2 \%)$ met criteria for eating disorder not otherwise specified (EDNOS; $M_{\text {age }}=21.38, S D=5.77$ ). The mean age of the total sample was $21.44(S D=5.85$, range $14-45)$ without significant age differences between the different ED subtypes $(F(3,487)=0.009$, $p=0.999)$. Patients were diagnosed by the psychiatrist based on a clinical interview, and the diagnoses were cross-validated by means of the Eating Disorder Evaluation Scale (Vandereycken, 1993). 


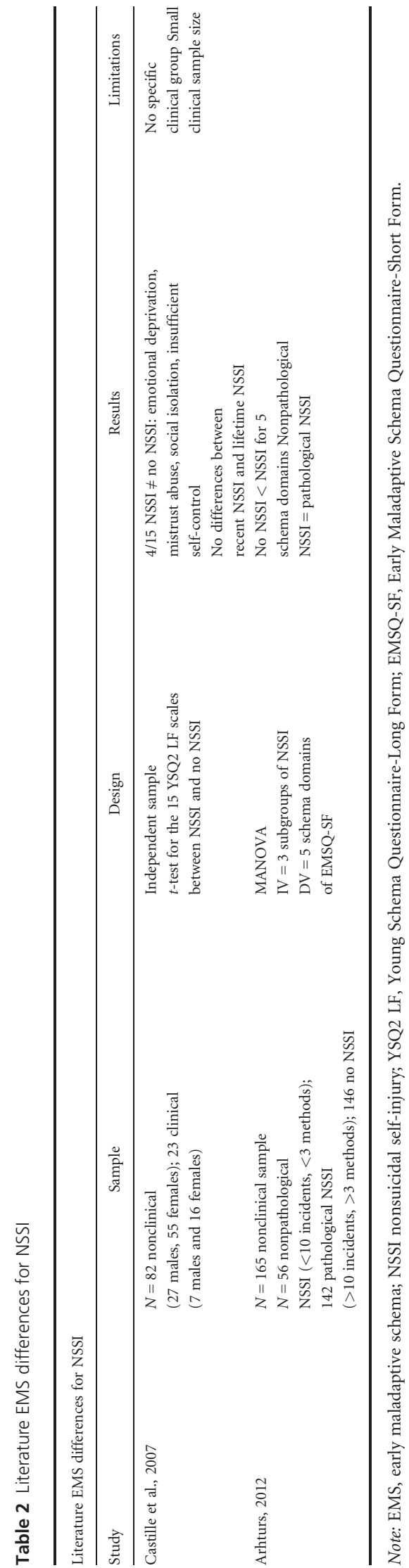

Patients in an acute state of mental crisis, patients with mental retardation and patients who could not complete the questionnaire because of practical or cognitive limitations were not included in this study.

The study was approved by the ethical committee of the hospital. At admission, all patients provided a written informed consent to use their data for scientific purposes. Questionnaires were filled out during the first 2 weeks after admission.

\section{Instruments}

The Young Schema Questionnaire-Long Form (YSQL2) was used to assess the EMS (Young and Brown, 1994; Dutch version: Young and Pijnaker, 1999) and consists of 205 items, which are divided over 16 subscales corresponding with the 16 EMS scales. For example, 'I haven't gotten love and attention.'-emotional deprivation-or 'I'm a failure.'-failure to achieve-or 'If I do what I want, I feel very uncomfortable.'-self-sacrifice-or 'I must meet all my responsibilities.'-unrelenting standards-or 'I get bored very easily.' —insufficient self-control. In order to avoid underestimation of psychopathology (Waller, Meyer, and Ohanian, 2001), we used the mean score format to calculate the scale scores. The items are rated on a 6-point Likert scale ranging from 1 'Completely untrue of me' to 6 'Describes me perfectly'. A number of studies have investigated the psychometric properties of the YSQL2, and overall, they show good results concerning reliability and validity of the 16 EMS scales (e.g. Schmidt, Joiner, Young, and Telch, 1995; Pauwels et al., 2013). In the present sample, the Cronbach's $\alpha$ coefficients of the subscales range from .81 to .95 , indicating good to very good internal consistency coefficients of the YSQL2 scales.

NSSI was assessed by means of the Self-Injury QuestionnaireTreatment Related (SIQ-TR; Claes and Vandereycken, 2007). This questionnaire asks respondents to indicate if they have deliberately injured themselves by five common methods (scratching, bruising, cutting, biting and burning) and how long ago they engaged in each of these behaviours (a week ago, a month ago, etc.). For each method endorsed, respondents are asked to specify the frequency of each method and the body parts injured. In this study, we included lifetime prevalence of NSSI, defined by the occurrence of at least one type/method of NSSI. The prevalence of recent NSSI was defined by the occurrence of at least one type/method of NSSI the past month. A score of 1 indicates the occurrence of lifetime/recent NSSI, and 0 indicates absence of NSSI. A NSSI severity index was calculated by making a sum score of the type/methods of NSSI ranging from 1 to 5 (Saraff and Pepper, 2014; Turner, Layden, Butler, and Chapman, 2013). The SIQ-TR shows good psychometric properties in ED samples (Claes and Vandereycken, 2007).

To control for eating disorder severity, the three eating disorder-related subscales of the Eating Disorder Inventory-2 (Garner, 1991) were used: drive for thinness, bulimia and body dissatisfaction.

\section{Analyses}

The prevalence of NSSI in patients with ED was explored by means of descriptive characteristics. The associations between the presence/absence of lifetime and recent NSSI and the four ED subtypes were calculated by means of a $\chi^{2}$ test statistic. 
We explored associations between YSQL2 schemas, NSSI severity indexes and ED severity indexes by means of the Pearson correlation coefficient. To investigate whether YSQL2 schemas differ in function of ED subtype, the presence/absence of NSSI and/or their interaction, a MANCOVA was performed with the YSQL2 scales as dependent variables and the ED subtype and presence/absence of NSSI and their interaction as independent variables. To investigate which ED subtypes statistically differed from each other, we performed Bonferroni post hoc tests ( $\alpha$ significant at $p=.003$ or $0.05 / 16)$. ED severity index was included as covariate. All analyses were performed by means of SPSS 20 .

\section{Results}

Of the patients with ED, 53.6\% have engaged in lifetime NSSI and $30 \%$ within the past month. Table 3 shows the prevalence rates of NSSI across the different ED subtypes. We found a significant difference between ED subtypes for both lifetime NSSI $\left[\chi^{2}(4\right.$, $N=487)=39.15, p<0.05]$ and recent NSSI $\left[\chi^{2}(4, N=487)\right.$
$=35.01, p<0.05]$, NSSI being less prevalent in restrictive patients (AN-R) compared with the other ED subtypes.

Pearson correlation analyses showed significant positive associations between all YSQL2 scales, NSSI and ED severity indexes (all $p<.003$ ), except for entitlement that showed no significant correlations. Overall, higher YSQL2 scores were associated with more severe NSSI and more severe ED symptomatology.

The results of the MANCOVA with YSQL2 as dependent variables and ED subtype, NSSI lifetime prevalence and their interaction as independent variables, and ED severity as covariate showed main effects of ED subtype (Wilks $\lambda=0.72, F(48,1369)$ $=3.39, p<.000 ; d=1.00$ ) and lifetime NSSI (Wilks $\lambda=0.88$, $F(16,460)=3.96, p<.000 ; d=1.00)$ but no significant interaction effect between ED subtype and NSSI (Wilks $\lambda=0.88, F(48,1369)$ $=1.23, p>.05 ; d=0.99$ ). Six of the 16 YSQL2 scales showed significant differences between the different ED subtypes. Patients with bulimia scored significantly higher on insufficient selfcontrol and emotional deprivation compared with restrictive patients, whereas restrictive patients scored significantly higher on social undesirability, failure to achieve, subjugation and

Table 3 Prevalence of NSSI in the four ED subtypes

\begin{tabular}{|c|c|c|c|c|c|}
\hline & \multicolumn{5}{|c|}{ Prevalence of NSSI in the four ED subtypes } \\
\hline & $\begin{array}{l}\text { ED sample }(N=487) \\
N(\% \text { total })\end{array}$ & $\begin{array}{c}\text { AN-R }(N=188) \\
(\% \text { total; \% diagnosis })\end{array}$ & $\begin{array}{c}\text { AN-BP }(N=80) \\
(\% \text { total; \% diagnosis })\end{array}$ & $\begin{array}{c}\text { BN }(N=112) \\
(\% \text { total; \% diagnosis })\end{array}$ & $\begin{array}{c}\text { EDNOS }(N=107) \\
(\% \text { total; \% diagnosis })\end{array}$ \\
\hline No lifetime NSSI & $226(46.4 \%)$ & $118(24 \% ; 63 \%)$ & $25(5 \% ; 31 \%)$ & $37(8 \% ; 33 \%)$ & $46(9 \% ; 43 \%)$ \\
\hline Lifetime NSSI & $261(53.6 \%)$ & $70(14 \% ; 37 \%)$ & $50(11 \% ; 67 \%)$ & $75(15 \% ; 67 \%)$ & $61(12 \% ; 57 \%)$ \\
\hline No recent NSSI & $341(70 \%)$ & $158(32 \% ; 80 \%)$ & $49(10 \% ; 61 \%)$ & $60(12 \% ; 54 \%)$ & $74(15 \% ; 70 \%)$ \\
\hline Recent NSSI & $146(30 \%)$ & $30(6 \% ; 16 \%)$ & $31(6 \%(39 \%)$ & $52(11 \% ; 46 \%)$ & $33(7 \% ; 31 \%)$ \\
\hline \multicolumn{6}{|l|}{ Scratching } \\
\hline Lifetime scratching & $167(34 \%)$ & $41(8 \% ; 22 \%)$ & $(7 \% ; 41 \%)$ & $49(10 \% ; 44 \%)$ & $44(9 \% ; 41 \%)$ \\
\hline Recent scratching & $78(16 \%)$ & $18(4 \% ; 10 \%)$ & $14(3 \% ; 18 \%)$ & $24(5 \% ; 21 \%)$ & $22(5 \% ; 21 \%)$ \\
\hline Main location & Arms $(52 ; 70 \%)$ & Arms $(10 ; 56 \%)$ & Arms $(9 ; 64 \%)$ & Arms $(14 ; 70 \%)$ & Arms $(19 ; 86 \%)$ \\
\hline Frequency/day & $<1(35 ; 45 \%)$ & $<1(9 ; 50 \%)$ & $<1(7 ; 50 \%)$ & $<1(14 ; 58 \%)$ & $1-2(16 ; 73 \%)$ \\
\hline \multicolumn{6}{|l|}{ Bruising } \\
\hline Lifetime bruising & $107(22 \%)$ & $22(5 \% ; 12 \%)$ & $26(5 \% ; 33 \%)$ & $29(6 \% ; 26 \%)$ & $30(6 \% ; 28 \%)$ \\
\hline Recent bruising & $37(8 \%)$ & $5(1 \% ; 3 \%)$ & $10(2 \% ; 13 \%)$ & $14(3 \% ; 13 \%)$ & $8(2 \% ; 8 \%)$ \\
\hline Main location & Arms $(13 ; 36 \%)$ & Arms $(2 ; 33 \%)$ & Legs $(4 ; 50 \%)$ & Torso $(5 ; 36 \%)$ & Arms $(5 ; 63 \%)$ \\
\hline Frequency/day & $<2(34 ; 90 \%)$ & $1-2(5 ; 83 \%)$ & $<1(6 ; 60 \%)$ & $<1(8 ; 57 \%)$ & $1-2(5 ; 62 \%)$ \\
\hline \multicolumn{6}{|l|}{ Cutting } \\
\hline Lifetime cutting & $191(39 \%)$ & $41(8 \% ; 22 \%)$ & $41(8 \% ; 51 \%)$ & $57(12 \% ; 51 \%)$ & $52(11 \% ; 49 \%)$ \\
\hline Recent cutting & $76(16 \%)$ & $10(2 \% ; 5 \%)$ & $19(4 \% ; 24 \%)$ & $27(6 \% ; 24 \%)$ & $20(4 \% ; 19 \%)$ \\
\hline Main location & Arms (46; 69\%) & Arms (8; 73\%) & Arms $(8 ; 50 \%)$ & Arms (15; 65\%) & Arms $(15 ; 88 \%)$ \\
\hline Frequency/day & $<1(49 ; 65 \%)$ & $<1(9 ; 90 \%)$ & $<1(13 ; 68 \%)$ & $<1(17 ; 63 \%)$ & $<2(20 ; 100 \%)$ \\
\hline \multicolumn{6}{|l|}{ Burning } \\
\hline Lifetime burning & $53(11 \%)$ & $7(1 \% ; 4 \%)$ & $13(3 \% ; 16 \%)$ & $22(5 \% ; 20 \%)$ & $11(2 \% ; 10 \%)$ \\
\hline Recent burning & $14(3 \%)$ & $1(0 \% ; 1 \%)$ & $5(1 \% ; 6 \%)$ & $6(1 \% ; 5 \%)$ & $2(0 \% ; 2 \%)$ \\
\hline Main location & Head $(11 ; 73 \%)$ & Head $(1 ; 100 \%)$ & Head $(4 ; 80 \%)$ & Head $(4 ; 67 \%)$ & Head $(2 ; 100 \%)$ \\
\hline Frequency/day & $<2(12 ; 96 \%)$ & $3-4(1 ; 100 \%)$ & $1-2(3 ; 60 \%)$ & $1-2(3 ; 50 \%)$ & $<1(2 ; 100 \%)$ \\
\hline \multicolumn{6}{|l|}{ Biting } \\
\hline Lifetime biting & $78(16.1 \%)$ & $18(4 \% ; 10 \%)$ & $20(4 \% ; 25 \%)$ & $20(4 \% ; 18 \%)$ & $20(4 \% ; 19 \%)$ \\
\hline Recent biting & $27(6 \%)$ & $6(1 \% ; 3 \%)$ & $6(1 \% ; 8 \%)$ & $8(2 \% ; 7 \%)$ & $7(1 \% ; 7 \%)$ \\
\hline Main location & Arms $(22 ; 76 \%)$ & Arms $(6 ; 100 \%)$ & Arms $(5 ; 83 \%)$ & Arms $(6 ; 67 \%)$ & Arms $(5 ; 76 \%)$ \\
\hline Frequency/day & $<1(13 ; 48 \%)$ & $<1(4 ; 67 \%)$ & $3-4(3 ; 50 \%)$ & $<1(4 ; 50 \%)$ & $<1(4 ; 57 \%)$ \\
\hline
\end{tabular}

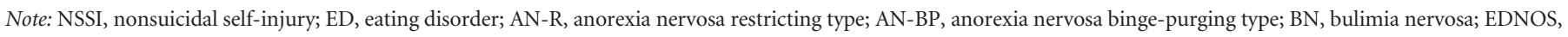
eating disorder not otherwise specified. 
Table 4 Means (standard deviations) of EMS scores in function of ED subtypes

\begin{tabular}{|c|c|c|c|c|c|c|c|}
\hline & \multicolumn{7}{|c|}{ Means (standard deviations) of EMS scores in function of ED subtypes } \\
\hline & NSSI & AN-R $M(S D)$ & AN-BP $M(S D)$ & $\mathrm{BN} M(S D)$ & EDNOS $M(S D)$ & $F$ value & Post hoc \\
\hline \multicolumn{8}{|l|}{ Disconnection and rejection } \\
\hline \multirow[t]{2}{*}{ Emotional deprivation } & NSSI LT & $20.07(0.89)$ & $21.54(1.30)$ & $24.36(1.12)$ & $25.52(1.08)$ & $5.76^{*}$ & $1<3 ; 1<4 ; 2<4$ \\
\hline & NSSI R & $19.11(1.15)$ & $23.40(1.30)$ & $24.86(1.16)$ & $26.47(1.18)$ & $7.10^{* *}$ & $1<2,3,4$ \\
\hline \multirow[t]{2}{*}{ Abandonment } & NSSI LT & $55.03(1.49)$ & $52.69(2.22)$ & $51.60(1.99)$ & $56.0(1.81)$ & & \\
\hline & NSSI R & $55.29(1.91)$ & $56.58(2.16)$ & $54.55(1.93)$ & $56.90(1.95)$ & & \\
\hline \multirow[t]{2}{*}{ Mistrust/abuse } & NSSI LT & $42.78(1.28)$ & $41.76(1.91)$ & $43.50(1.70)$ & $43.76(1.54)$ & & \\
\hline & NSSI R & $42.85(1.63)$ & $45.31(1.84)$ & $45.00(1.64)$ & $45.91(1.66)$ & & \\
\hline \multirow[t]{2}{*}{ Social isolation } & NSSI LT & $30.96(0.91)$ & $30.69(1.36)$ & $28.05(1.22)$ & $31.57(1.10)$ & & \\
\hline & NSSI R & $31.78(1.15)$ & $33.27(1.31)$ & $29.14(1.16)$ & $32.57(1.18)$ & & \\
\hline \multirow[t]{2}{*}{ Defectiveness/shame } & NSSI LT & $47.81(1.40)$ & $44.20(2.09)$ & $41.87(1.86)$ & $46.26(1.69)$ & & \\
\hline & NSSI R & $49.51(1.78)$ & $48.43(2.01)$ & $44.50(1.79)$ & $49.06(1.81)$ & & \\
\hline \multicolumn{8}{|l|}{ Impaired autonomy and performance } \\
\hline \multirow[t]{2}{*}{ Social undesirability } & NSSI LT & $33.58(0.70)$ & $29.69(1.04)$ & $26.44(0.93)$ & $30.96(0.84)$ & $11.64^{* *}$ & $1>2,3,4 ; 2=4>3$ \\
\hline & NSSI R & $34.93(0.89)$ & $31.38(1.00)$ & $27.23(0.89)$ & $32.02(0.90)$ & $11.77^{\star *}$ & $1>2=4>3$ \\
\hline \multirow[t]{2}{*}{ Failure to achieve } & NSSI LT & $34.39(0.91)$ & $30.27(1.36)$ & $28.19(1.22)$ & $32.17(1.10)$ & $5.45^{*}$ & $1>2 ; 1>3 ; 3<4$ \\
\hline & NSSI R & $35.16(1.16)$ & $32.84(1.31)$ & $29.05(1.17)$ & $33.81(1.18)$ & & \\
\hline \multirow[t]{2}{*}{ Dependence/incompetence } & NSSI LT & $45.57(1.32)$ & $44.43(1.97)$ & $41.59(1.76)$ & $43.40(1.59)$ & & \\
\hline & NSSI R & $46.40(1.68)$ & $47.08(1.90)$ & $42.37(1.69)$ & $46.18(1.72)$ & & \\
\hline \multirow[t]{2}{*}{ Vulnerability to harm } & NSSI LT & $33.57(1.04)$ & $33.88(1.55)$ & $29.57(1.38)$ & $34.56(1.25)$ & & \\
\hline & NSSI R & $34.70(1.32)$ & $36.76(1.49)$ & $30.93(1.33)$ & $35.33(1.35)$ & & \\
\hline \multirow[t]{2}{*}{ Enmeshment } & NSSI LT & $29.26(0.93)$ & $27.17(1.39)$ & $24.21(1.24)$ & $26.36(1.13)$ & & \\
\hline & NSSI R & $29.57(1.19)$ & $28.34(1.35)$ & $25.40(1.20)$ & $27.63(1.22)$ & & \\
\hline \multicolumn{8}{|l|}{ Impaired limits } \\
\hline \multirow[t]{2}{*}{ Entitlement/grandiosity } & NSSI LT & $28.68(0.73)$ & $27.07(1.10)$ & $28.21(0.98)$ & $28.54(0.89)$ & & \\
\hline & NSSI R & $28.89(0.93)$ & $27.12(1.06)$ & $28.56(0.94)$ & $27.92(0.95)$ & & \\
\hline \multirow[t]{2}{*}{ Insufficient self-control/self-discipline } & NSSI LT & $39.69(0.99)$ & $41.24(1.48)$ & $47.33(1.32)$ & $43.57(1.19)$ & $7.05^{\star *}$ & $1<4<3 ; 2<3$ \\
\hline & NSSI R & $39.16(1.25)$ & $43.30(1.42)$ & $47.90(1.27)$ & $43.93(1.28)$ & $7.42^{\star \star}$ & $1<(2=4)<3$ \\
\hline \multicolumn{8}{|l|}{ Other directedness } \\
\hline \multirow[t]{2}{*}{ Subjugation } & NSSI LT & $34.18(0.86)$ & $29.30(1.29)$ & $27.50(1.15)$ & $31.24(1.04)$ & $7.25^{\star \star}$ & $1>2,3,4 ; 3<4$ \\
\hline & NSSI R & $35.15(1.10)$ & $31.51(1.25)$ & $28.37(1.11)$ & $32.72(1.12)$ & $5.94^{* *}$ & $1>2,3 ; 3<4$ \\
\hline \multirow[t]{2}{*}{ Self-sacrifice } & NSSI LT & $65.72(1.30)$ & $62.99(1.94)$ & $59.69(1.73)$ & $60.80(1.57)$ & & \\
\hline & NSSI R & $66.69(1.66)$ & $65.42(1.88)$ & $61.58(1.68)$ & $63.13(1.70)$ & & \\
\hline \multicolumn{8}{|l|}{ Over-vigilance and inhibition } \\
\hline \multirow[t]{2}{*}{ Emotional inhibition } & NSSI LT & $27.70(0.67)$ & $27.41(1.00)$ & $25.66(0.89)$ & $26.73(0.81)$ & & \\
\hline & NSSI R & $29.22(0.85)$ & $29.27(0.96)$ & $27.12(0.85)$ & $27.94(0.86)$ & & \\
\hline \multirow[t]{2}{*}{ Unrelenting standards } & NSSI LT & $68.36(1.30)$ & $60.55(1.95)$ & $56.65(1.74)$ & $58.65(1.57)$ & $11.66^{* *}$ & $1>2=3=4$ \\
\hline & NSSI R & $70.40(1.65)$ & $62.54(1.87)$ & $58.42(1.67)$ & $59.61(1.69)$ & $9.76^{* *}$ & $1>2,3,4$ \\
\hline
\end{tabular}

Note: AN-R (1), AN-BP (2), BN (3), EDNOS (4). EMS, early maladaptive schema; NSSI, nonsuicidal self-injury; ED, eating disorder; AN-R, anorexia nervosa restricting type; AN-BP, anorexia nervosa binge-purging type; BN, bulimia nervosa; EDNOS, eating disorder not otherwise specified.

${ }^{*} p<0.003$ and ${ }^{* *} p<0.001$.

unrelenting standards compared with patients with bulimia (Table 4). Additionally, for lifetime NSSI, all EMS scales with exception of entitlement and insufficient self-control were significantly higher in patients with ED with NSSI compared with patients with ED without NSSI $(p<.003)$ (Table 5$)$. When repeating the MANCOVA with recent NSSI (instead of lifetime NSSI), all EMS scales with the exception of entitlement, insufficient selfcontrol, emotional deprivation and enmeshment were significantly higher in patients with ED with NSSI compared with patients without NSSI $(p<.003)$ (Table 5).

\section{Discussion}

The main focus of this paper was to investigate EMS differences between ED subtypes and the role of recent/lifetime NSSI. First, we explored the prevalence of NSSI, lifetime as well as recent, across the different ED subtypes and found that both forms of NSSI were more prevalent in patients with bulimia compared with restrictive patients with AN. This finding was in line with the findings of Svirko and Hawton (2007) and Islam et al. (2015), who reported more NSSI in patients with bulimic ED compared with restrictive patients. According to Claes, Vandereycken, and Vertommen (2001), the higher prevalence of NSSI in patients with bulimic/purging ED was partially explained by higher levels of impulsivity in both patients with NSSI and bulimia.

Second, we investigated EMS in function of ED subtype and the presence/absence of recent/lifetime NSSI. In contrast with previous studies, after controlling for ED severity, we found significant differences between ED subtypes and six EMSs. Compared with 
Table 5 Means (standard deviations) of EMS scores in function of NSSI

\begin{tabular}{|c|c|c|c|c|c|}
\hline & \multicolumn{5}{|c|}{ Means (standard deviations) of EMS scores in function of NSSI } \\
\hline & NSSI LT/R & Without NSSI $M(S D)$ & With NSSI $M(S D)$ & $F$ value & Post hoc \\
\hline \multicolumn{6}{|l|}{ Disconnection and rejection } \\
\hline \multirow[t]{2}{*}{ Emotional deprivation } & NSSI LT & $20.90(0.87)$ & $24.85(0.71)$ & $12.14^{*}$ & $0<1$ \\
\hline & NSSI R & $22.73(0.67)$ & $24.18(0.98)$ & & \\
\hline \multirow[t]{2}{*}{ Abandonment } & NSSI LT & $49.24(1.45)$ & $58.42(1.19)$ & $23.44^{* *}$ & $0<1$ \\
\hline & NSSI R & $52.04(1.12)$ & $59.62(1.63)$ & $14.69^{* *}$ & $0<1$ \\
\hline \multirow[t]{2}{*}{ Mistrust/abuse } & NSSI LT & $38.87(1.24)$ & $47.04(1.02)$ & $25.40^{* *}$ & $0<1$ \\
\hline & NSSI R & $41.23(0.95)$ & $48.31(1.39)$ & $17.58^{\star *}$ & $0<1$ \\
\hline \multirow[t]{2}{*}{ Social isolation } & NSSI LT & $27.71(0.89)$ & $32.93(0.72)$ & $20.42^{* *}$ & $0<1$ \\
\hline & NSSI R & $28.92(0.67)$ & $34.46(0.98)$ & $21.43^{* *}$ & $0<1$ \\
\hline \multirow[t]{2}{*}{ Defectiveness/shame } & NSSI LT & $39.51(1.36)$ & $50.56(1.12)$ & $38.83^{* *}$ & $0<1$ \\
\hline & NSSI R & $42.21(1.04)$ & $53.54(1.51)$ & $37.95^{* *}$ & $0<1$ \\
\hline \multicolumn{6}{|l|}{ Impaired autonomy and performance } \\
\hline \multirow[t]{2}{*}{ Social undesirability } & NSSI LT & $27.87(0.68)$ & $32.47(0.55)$ & $27.08^{* *}$ & $0<1$ \\
\hline & NSSI R & $28.85(0.52)$ & $33.94(0.75)$ & $30.72^{\star *}$ & $0<1$ \\
\hline \multirow[t]{2}{*}{ Failure to achieve } & NSSI LT & $28.43(0.89)$ & $34.08(0.73)$ & $23.86^{* *}$ & $0<1$ \\
\hline & NSSI R & $29.58(0.67)$ & $35.85(0.98)$ & $27.41^{* *}$ & $0<1$ \\
\hline \multirow[t]{2}{*}{ Dependence/incompetence } & NSSI LT & $39.97(1.28)$ & $47.52(1.05)$ & $20.37^{* *}$ & $0<1$ \\
\hline & NSSI R & $41.81(0.98)$ & $49.20(1.43)$ & $18.05^{\star *}$ & $0<1$ \\
\hline \multirow[t]{2}{*}{ Vulnerability to harm } & NSSI LT & $29.55(1.01)$ & $36.14(0.83)$ & $25.05^{\star *}$ & $0<1$ \\
\hline & NSSI R & $31.16(0.77)$ & $37.79(1.12)$ & $23.57^{* *}$ & $0<1$ \\
\hline \multirow[t]{2}{*}{ Enmeshment } & NSSI LT & $24.55(0.90)$ & $28.94(0.74)$ & $13.86^{\star *}$ & $0<1$ \\
\hline & NSSI R & $26.21(0.69)$ & $29.26(1.01)$ & & \\
\hline \multicolumn{6}{|l|}{ Impaired limits } \\
\hline \multirow[t]{2}{*}{ Entitlement/grandiosity } & NSSI LT & $28.19(0.71)$ & $28.05(0.58)$ & & \\
\hline & NSSI R & $28.21(0.54)$ & $28.04(0.79)$ & & \\
\hline \multirow[t]{2}{*}{ Insufficient self-control/self-discipline } & NSSI LT & $41.34(0.96)$ & $44.58(0.78)$ & & \\
\hline & NSSI R & $42.51(0.73)$ & $44.62(1.07)$ & & \\
\hline \multicolumn{6}{|l|}{ Other directedness } \\
\hline \multirow[t]{2}{*}{ Subjugation } & NSSI LT & $27.99(0.84)$ & $33.12(0.69)$ & $21.94^{* *}$ & $0<1$ \\
\hline & NSSI R & $29.46(0.64)$ & $34.41(0.94)$ & $18.86^{* *}$ & $0<1$ \\
\hline \multirow[t]{2}{*}{ Self-sacrifice } & NSSI LT & $58.24(1.26)$ & $66.37(1.03)$ & $24.42^{* *}$ & $0<1$ \\
\hline & NSSI R & $60.96(0.97)$ & $67.45(1.42)$ & $14.18^{\star *}$ & $0<1$ \\
\hline \multicolumn{6}{|l|}{ Over-vigilance and inhibition } \\
\hline \multirow[t]{2}{*}{ Emotional inhibition } & NSSI LT & $24.40(0.65)$ & $29.44(0.53)$ & $35.05^{\star *}$ & $0<1$ \\
\hline & NSSI R & $25.50(0.49)$ & $31.28(0.72)$ & $43.41^{\star *}$ & $0<1$ \\
\hline \multirow[t]{2}{*}{ Unrelenting standards } & NSSI LT & $57.79(1.27)$ & $64.31(1.04)$ & $15.58^{\star *}$ & $0<1$ \\
\hline & NSSI R & $59.55(0.96)$ & $65.93(1.41)$ & $13.90^{* *}$ & $0<1$ \\
\hline
\end{tabular}

Note: Without NSSI (0), With NSSI (1). EMS, early maladaptive schema; NSSI, nonsuicidal self-injury.

${ }^{*} p<0.003$ and ${ }^{* *} p<0.001$.

restrictive patients, patients with bulimia scored significantly higher on the EMSs insufficient self-control and emotional deprivation, which are closely related to the impulse and interpersonal features of the cluster B personality disorders (Pauwels et al., 2013). Compared with patients with bulimia, restrictive patients scored significantly higher on the EMSs: failure to achieve, social undesirability, subjugation and unrelenting standards that are closely related to cluster C personality disorders (Pauwels et al., 2013). Although little is known about the relation between NSSI and EMS, our results show a strong association between lifetime prevalence of NSSI and higher levels of EMS within the ED sample. In line with previous studies in nonclinical samples (Arhturs, 2012; Castille et al., 2007), a lifetime history of NSSI was related to higher levels of EMS, which can be related to more personality pathology, irrespective of ED subtype (Pauwels et al., 2013).
Although less pronounced, results were very similar for recent NSSI. These findings confirm the hypothesis that the presence of NSSI in patients with ED is related to higher levels of EMS and because of the strong association between EMS and personality pathology (Pauwels et al., 2013) presumably to a higher amount of (personality) psychopathology, regardless of the severity of the ED (Claes and Muehlenkamp, 2014; Islam et al., 2015).

Despite the strength of our study, it was not without limitations. First, the present study did not include all ED subtypes (such as binge eating disorder) and the patients with ED were not equally distributed over the different ED subtypes. Moreover, we did not control for axis I comorbidity, and it was a female only sample. Second, we did not have any information of previous treatment experiences that could have influenced the identification of EMSs and the prevalence of recent NSSI (e.g. which could 
be reduced by to the more secure context of the admission). However, despite these shortcomings, this study was the first to investigate EMS differences in function of ED subtype and the role of NSSI. Whereas bulimic ED symptoms seem to be related to cluster B EMSs like insufficient self-control and restrictive ED symptoms seem to be related to cluster C EMSs like unrelenting standards, schema therapy is advised for the treatment of patients with ED. Lifetime/recent NSSI was related to higher levels of EMS compared with patients without NSSI, which could be associated with greater severity of personality psychopathology within NSSI given the strong association between EMS and personality pathology (Pauwels et al., 2013; Islam et al., 2015). This association of NSSI with greater severity of personality psychopathology might be an explanation for the finding that treatment outcomes for ED with cognitive and behaviour therapy are often poor and as Pugh (2015) suggest may be attributed to more complex presentations or pronounced negative self-beliefs. The specific associations between NSSI functions or methodology and EMS could be of particular interest in future research for a better understanding of the associations between EMS and NSSI in ED. However, based on these results, assessing (lifetime and recent) NSSI in patients with ED may be an important factor to take into account when starting clinical therapy as it is linked with a more severe or complex presentation of core beliefs. Furthermore, an important clinical implication in ED treatment will be to look beyond the ED symptoms and to target the underlying EMS that could differ according to different ED subtype.

\section{REFERENCES}

American Psychiatric Association (2000). Diagnostic and Statistical Manual of Mental Disorders: DSM-IV-TR R. Washington, DC: American Psychiatric Association.

Arhturs, S.D. (2012). Personality and early maladaptive schemas differentiating persons who engage in infrequent versus pathological non-suicidal self-injury. (Master thesis). Retrieved from http://thesis.lakeheadu.ca:8080/handle/2453/539

Castille, K., Prout, M., Marczyk, G., Shmidheiser, M., Yoder, S., \& Howlett, B. (2007). The early maladaptive schemas of selfmutilators: implications for therapy. Journal of Cognitive Psychotherapy, 21, 58-71.

Claes, L., \& Muehlenkamp, J. J. (2014). Non-suicidal self-injury in eating disorders. Germany, Heidelberg: Springer.

Claes, L., \& Vandereycken, W. (2007). Self-injurious behavior: differential diagnosis and functional differentiation. Comprehensive Psychiatry, 48, 137-144.

Claes, L., Vandereycken, W., \& Vertommen, H. (2001). Self-injurious behaviors in eating-disordered patients. Eating Behaviors, 2, 263-272.

Claes, L., Vandereycken, W., \& Vertommen, H. (2005). Impulsivityrelated traits in eating disorder patients. Personality and Individual Differences, 39, 739-749.

Cooper, M., \& Hunt, J. (1998). Core beliefs and underlying assumptions in bulimia nervosa and depression. Behaviour Research and Therapy, 36, 895-898.

Cooper, M. J., Wells, A., \& Todd, G. (2004). A cognitive model of bulimia nervosa. British Journal of Clinical Psychology, $43,1-16$.

Damiano, S. R., Reece, J., Reid, S., Atkins, L., \& Patton, G. (2015). Maladaptive schemas in adolescent females with anorexia nervosa and implications for treatment. Eating Behaviors, $16,64-71$.
Dingemans, A. E., Spinhoven, P., \& Van Furth, E. F. (2006). Maladaptive core beliefs and eating disorder symptoms. Eating Behaviors, 7, 258-265.

Garner, D. M. (1991). Eating disorder inventory-2. Odessa, FL: psychological assessment resources.

Godt, K. (2002). Personality disorders and eating disorders: the prevalence of personality disorders in 176 female outpatients with eating disorders. European Eating Disorders Review, 10, 102-109.

Islam, M. A., Steiger, H., Jimenez-Murcia, S., Israel, M., Granero, R., Agüera, Z., et al. (2015). Non-suicidal self-injury in different eating disorder types: relevance of personality traits and gender. $\mathrm{Eu}$ ropean Eating Disorders Review, 23(6), 553-560.

Jacobson, C. M., \& Luik, C. C. (2014). Epidemiology and sociocultural aspects of non-suicidal self-injury and eating disorders. In 1.2., Non-suicidal self-injury in eating disorders (pp. 19-34). Berlin: Heidelberg Springer.

Luck, A., Waller, G., Meyer, C., Ussher, M., \& Lacey, H. (2005). The role of schema processes in the eating disorders. Cognitive Therapy and Research, 29, 717-732.

Pauwels, E., Claes, L., Smits, D., Dierckx, E., Muehlenkamp, J. J., Peuskens, H., et al. (2013). Validation and reliability of the young schema questionnaire in a flemish inpatient eating disorder and alcohol and substance use disorder sample. Cognitive Therapy and Research, 37, 647-656.

Pugh, M. (2015). A narrative review of schemas and schema therapy outcomes in the eating disorders. Clinical Psychology Review, 39, $30-41$.

Saraff, P. D., \& Pepper, C. M. (2014). Functions, lifetime frequency, and variety of methods of non-suicidal self-injury among college students. Psychiatry Research, 219(2), 298-304.

Schmidt, N. B., Joiner, T. E., Young, J. E., \& Telch, M. J. (1995). The Schema Questionnaire: investigation of psychometric properties and the hierarchical structure of a measure of maladaptive schemas. Cognitive Therapy and Research, 19, 295-321.
Svirko, E., \& Hawton, K. (2007). Self-injurious behavior and eating disorders: the extent and nature of the association. Suicide and Life-Threatening Behavior, 37, 409-421.

Turner, B. J., Layden, B. K., Butler, S. M., \& Chapman, A. L. (2013). How often, or how many ways: clarifying the relationship between non-suicidal self-injury and suicidality. Archives of Suicide Research, 17(4), 397-415.

Vandereycken, W. (1993). The eating disorder evaluation scale (EDES). Eating Disorders, 1, 115-122.

Voderholzer, U., Schwartz, C., Thiel, N., Kuelz, A. K., Hartmann, A., Scheidt, C. E., et al. (2014). A comparison of schemas, schema modes and childhood traumas in obsessive-compulsive disorder, chronic pain disorder and eating disorders. Psychopathology, 47, 24-31.

Waller, G., Ohanian, V., Meyer, C., \& Osman, S. (2000). Cognitive content among bulimic women: the role of core beliefs. International Journal of Eating Disorders, 28, 235-241.

Waller, G. (2003). Schema-level cognitions in patients with binge eating disorder: a case control study. International Journal of Eating Disorders, 33, 458-464.

Waller, G., Meyer, C., \& Ohanian, V. (2001). Psychometric properties of the long and short versions of the Young Schema Questionnaire: core beliefs among bulimic and comparison women. Cognitive Therapy and Research, 25, 137-147.

Young, J. E., \& Brown, G. (1994). Young Schema-Questionnaire2nd ed.. In J. E. Young (Ed.), Cognitive therapy for personality disorders: a schema-focused approach (pp. 63-76)Rev. ed., pp. Sarasota, FL: Professional Resource Press.

Young, J. E., Klosko, J. S., \& Weishaar, M. E. (2003). Schema therapy: a practitioner's guide. New York: Guilford Press.

Young, J. E., \& Pijnaker, H. (1999). Cognitieve therapie voor persoonlijkheidsstoornissen: Een schemagerichte benadering [Cognitive therapy for personality disorders: a schema oriented approach]. Houten, Netherlands: Bohn Stafleu Van Loghum. 